\title{
Early Warning And On-Line Mapping For Flood Events
}

\author{
D. Mioc a, f , B. Nickerson b, F. Anton c, E. MacGillivray d, A. Morton d, \\ D. Fraser a, P. Tang e and A. Kam a \\ a Department of Geodesy and Geomatics Engineering, University of New Brunswick, \\ Canada \\ ${ }^{b}$ Faculty of Computer Science, University of New Brunswick, \\ Canada \\ c Department of Informatics and Mathematical Modeling, Technical University of Denmark, \\ Denmark \\ ${ }^{d}$ Emergency Measures Organization, Victoria Health Centre, 65 Brunswick Street, \\ Fredericton, NB, \\ Canada \\ ${ }^{e}$ New Brunswick Department of Environment, Marysville Place, Fredericton, NB, \\ Canada \\ $f$ National Space Institute, Technical University of Denmark, \\ Denmark
}

\section{Introduction}

Floods are common natural disasters throughout the world. Each year they cause considerable damage to people's lives and properties. In the spring of 1973, the lower Saint John River in the Fredericton area (New Brunswick, Canada) experienced its worst ever

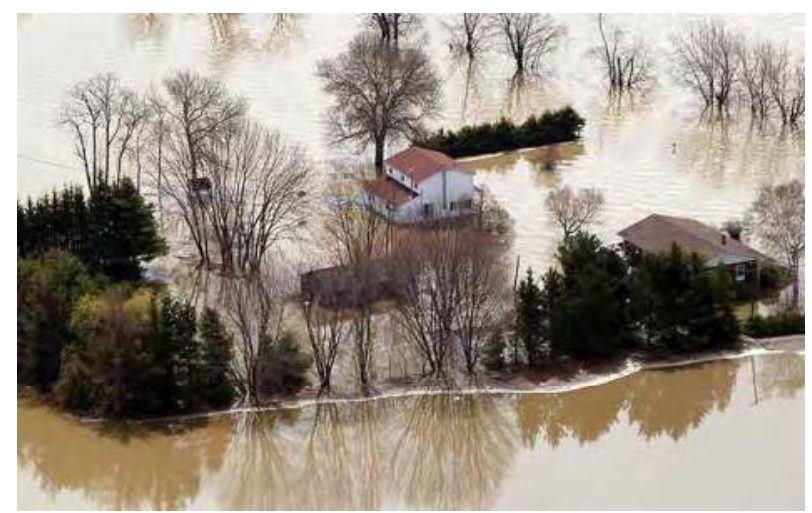

Fig. 1. The impact of flooding in Fredericton, New Brunswick in Spring, 2008 
recorded flooding, resulting in economic losses of CAD 31,9 million, and the loss of one life (CIWD, 1974). At the peak of the flood, private houses and public churches were flooded, and roads and bridges were damaged.

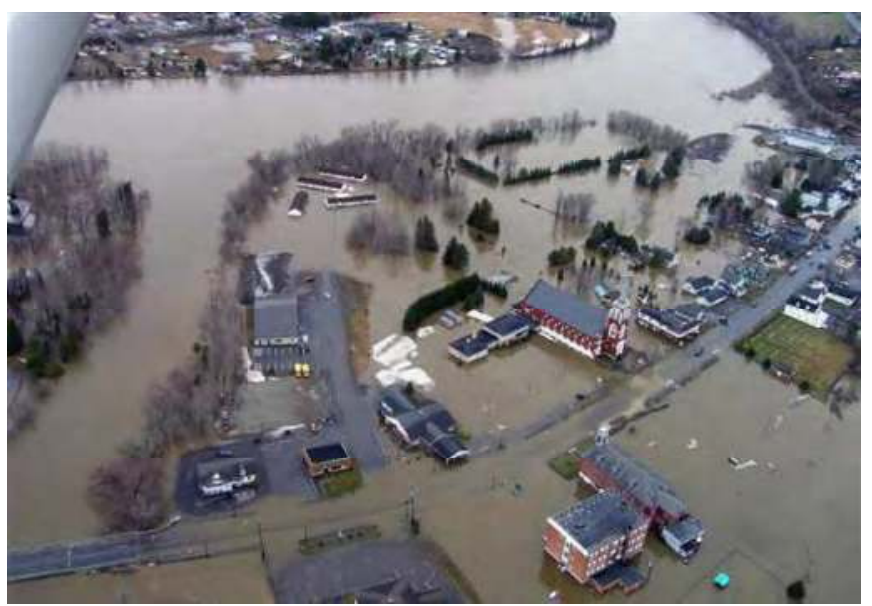

Fig. 2. Flooding of St. John River in 2008

Since 1973 other floods have caused another three lives lost and more than CAD 68.9 million in damage.

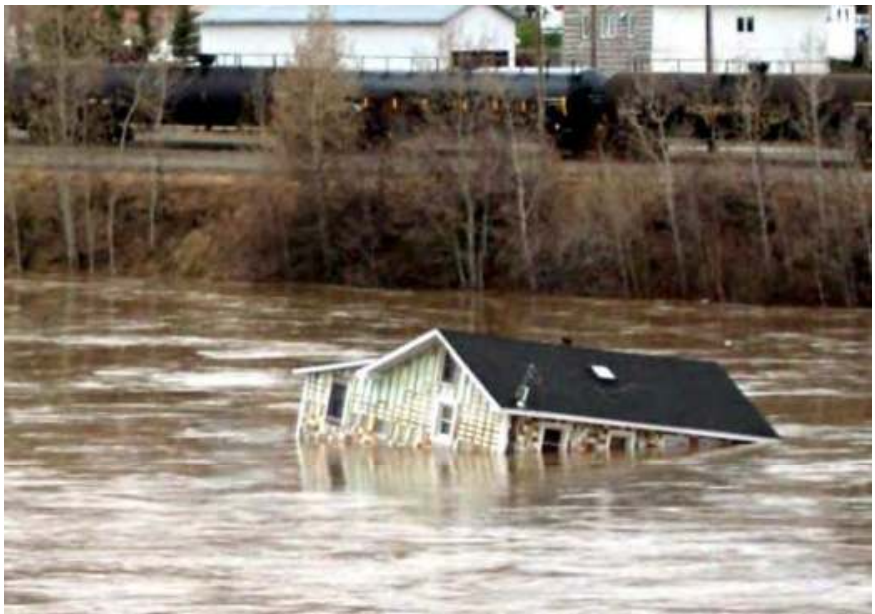

Fig. 3. One house taken by the flood in 2008

In May 2008, heavy rains combined with melted snow have overwhelmed the St. John River, which is 673 kilometres long, and brought water levels to a height that many regions have not seen in more than three decades. Homes have floated off their foundation and travelled downstream, while 600 families and individuals have been evacuated (see Figures 1, 2 and 3). The determination of the financial cost of damages caused by this flooding is still not finalized. 
Flood forecasting has been proven to reduce the property damage and the loss of lives (Sanders et al., 2005). The recent advances in forecasting for flood warning (Moore et al., 2005) have shown that is possible to integrate rainfall modeling and forecasting with flood forecasting and warning. The research paper on World Wide Web based hydrological model for flood prediction using GIS (Al-Sabhan et al., 2003) gives an excellent overview of current research advances and a new on-line available prototype that combined hydrological modeling with Internet technology.

However, in this research we didn't try to customize any of the existing flood forecasting models described in the literature as it is proven to be very difficult and very specific to the different modeling tools that are used (Al-Sabhan et al., 2003). Instead, we implemented the automatization of specific existing processes, workflows and modeling tools for flood forecasting and monitoring in the New Brunswick Department of Environment.

The Saint John River Forecast System operated by the Department of Environment Hydrology Centre is monitoring and predicting flood events along the Saint John River. The Hydrology Centre team uses hydrologic modeling software to predict water levels for the next 24 and 48 hours along the lower Saint John River Valley by incorporating climate data, weather forecast data, snow data and flow data.

However, the predicted water levels provided by this system cannot satisfy the requirements of the decision support system for flood events. The system neither directly displays the areas affected by flooding, nor shows the difference between two flood events. Based on the water levels, it is hard for users to directly determine which houses, roads, and structures will be affected by the predicted flooding. To deal with this problem, it is necessary to visualize the output from hydrological modeling in a Geographic Information System (GIS). GISs have powerful tools that allow the predicted flood elevations to be displayed as a map showing the extent of the inundation. After the interfaces for the visualization of the impact of flood events are designed, a computerized system is developed that predicts the extent of floods and dynamically displays near-real-time flood information for decision makers and the general public.

To improve flood prediction for Saint John River, we developed a Web GIS based decision support system for flood prediction and monitoring. In this paper, we present the methods for data integration, floodplain delineation, and online map interfaces. This paper is organized as follows: in Section 2, we briefly describe the Saint John River floodplain and in Section 3, we present hydrological modelling for flood forecasting. In section 4, we present the conceptual model of the flood prediction and monitoring system and in section 5 , we explain the integration of hydrological modelling and GIS. Subsection 5.1 presents a Webbased interface for dynamic flood prediction monitoring and mapping that can dynamically display observed and predicted flood extents for decision makers and the general public. In section 6, we present our conclusions, and in section 7 our acknowledgments.

\section{Saint John River Floodplain}

The Saint John River lies in a broad arc across South-Eastern Quebec, northern Maine and western New Brunswick. Its Canadian portion extends from a point on the international 
boundary with the State of Maine in United States to the Bay of Fundy. It drains a total watershed area of $54.600 \mathrm{~km}^{2}$. The river is about $700 \mathrm{~km}$ long, and the total fall from its headwaters to the city of Saint John is about $482 \mathrm{~m}$. The slope of the river gradually decreases from about 1,5 metres per kilometre in the headwaters to 0,4 metres per kilometre in the reach above Fredericton (see Figure 4).

The study area of this research is the floodplain area along a $90 \mathrm{~km}$ long section of the river from Fredericton to Oak Point and the French, Grand, Indian and Maquapit lakes. Flooding has been a significant problem for this area for a long time. From the largest and best documented flood occurred between April and May 1973, the greatest flood damage areas are located within the proposed study area and include:

a) Fredericton south of the former CNR Bridge,

b) Nashwaaksis Subdivision,

c) East Bank downstream of the Princess Margaret Bridge, and

d) the Lincoln area (ENB-MAL, 1979).

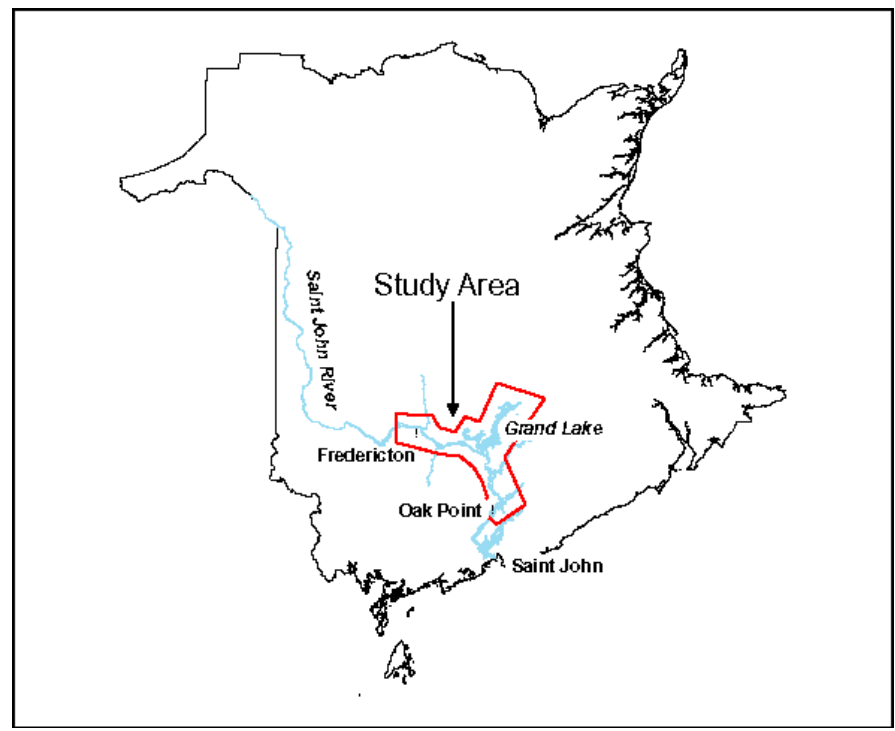

Fig. 4. Overview of Saint John River watershed

\section{Hydrological Modelling for Flood Forecasting}

Flood forecasting on the Saint John River is performed by the Hydrology Centre of the New Brunswick Department of Environment in co-operation from interprovincial and international agencies. Both hydrologic and hydraulic models are utilized in order to forecast water levels in the lower Saint John River. The basic component of the system is the U.S. Army Corps of Engineers' Streamflow Synthesis and Reservoir Regulation (SSARR) model. The Simulated Open Channel Hydraulics (SOCH) model of the Tennessee Valley Authority and the Dynamic Wave Operational (DWOPER) model (Fread, 1992; Fread, 1993; Fread and Lewis, 1998) of the National Weather Service are also used. 


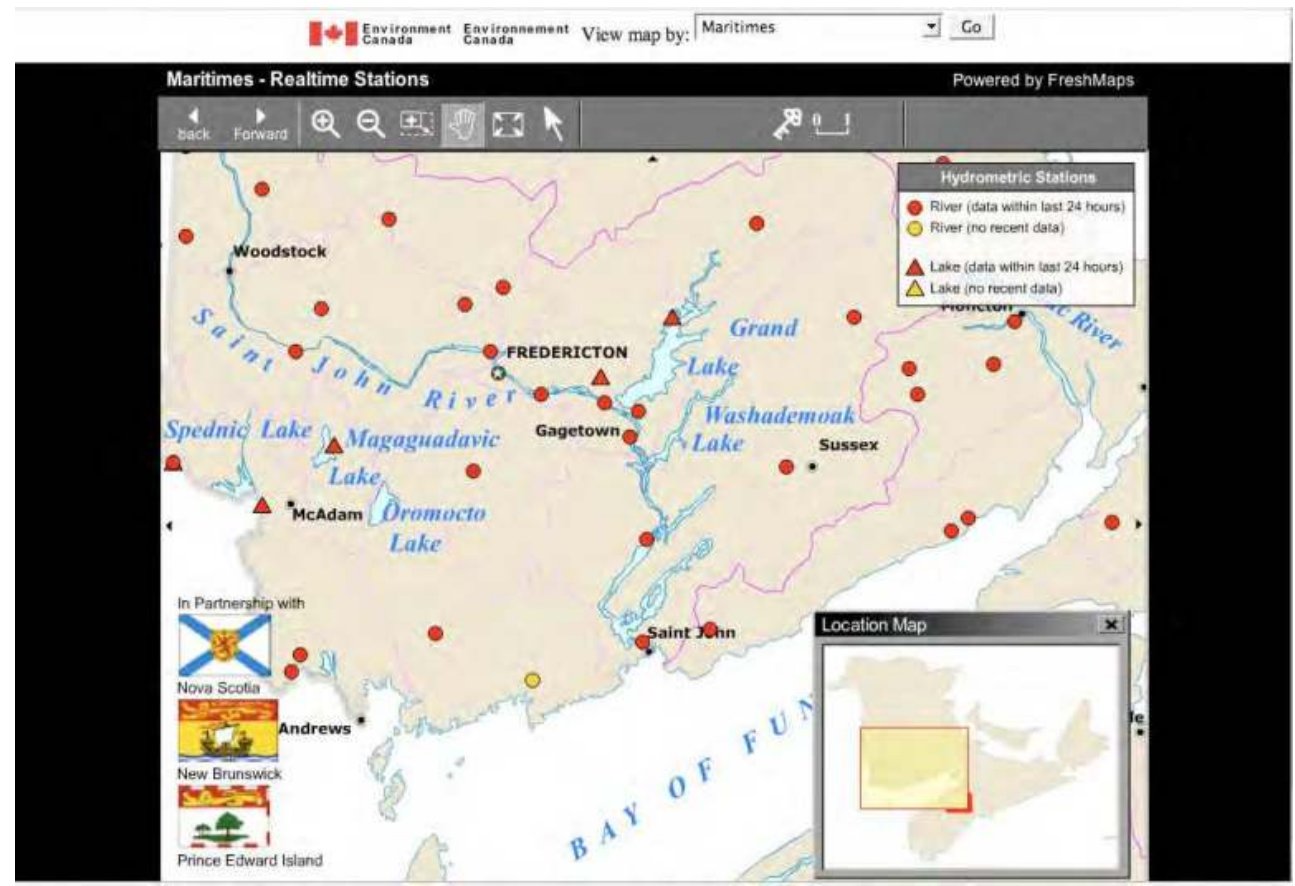

Fig. 5. The map of existing water gauges in New Brunswick
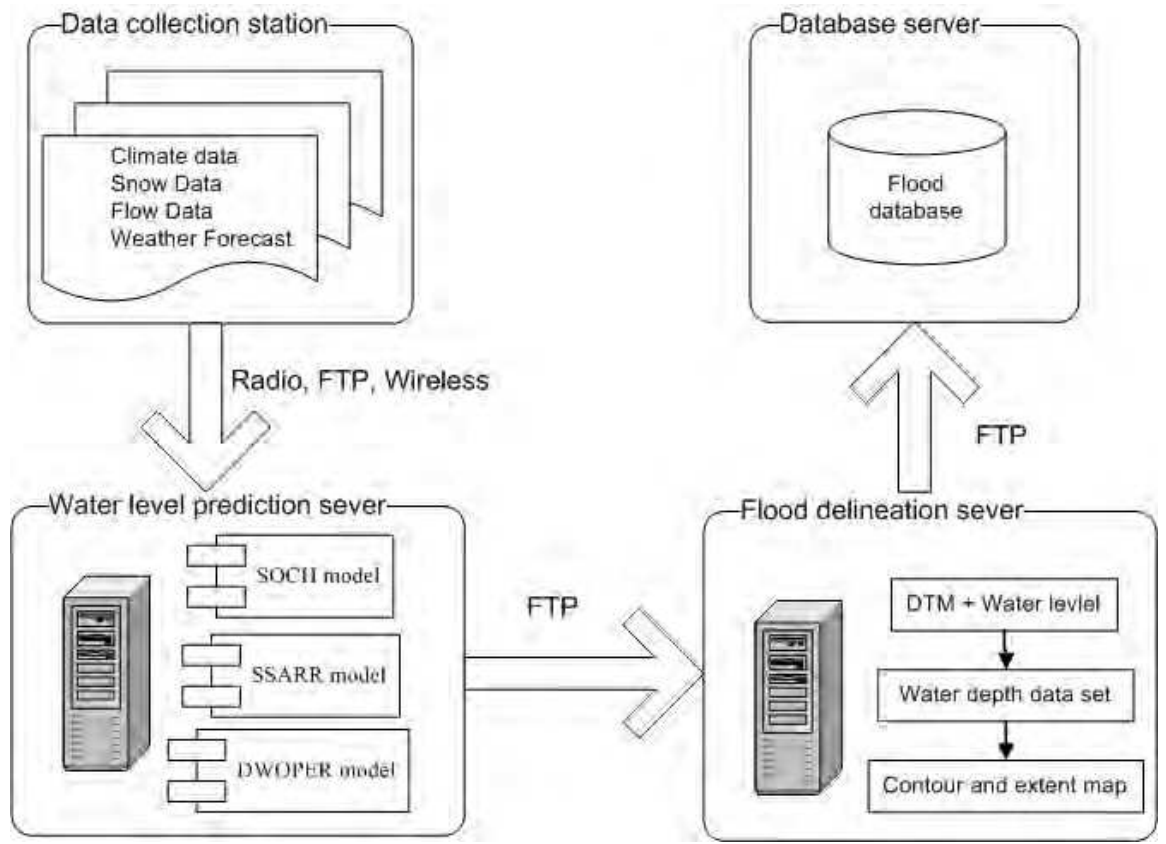

Fig. 6. The operational model of flood forecasting in New Brunswick River Watch 
The Hydrology Centre monitors the water levels, stream flows and climate with partner agencies, and coordinates a co-operative snow survey with reports for the entire Saint John River Basin. There are networks of 25 stream-flow gauges, 16 water level gauges, and 43 climate stations throughout the Saint John River Basin (see Figure 5). The data are transmitted to the Hydrology Centre through a variety of telecommunication systems and protocols (see Figure 6). The data are processed and analyzed before being accepted as input data to the models.

Comparisons of predicted and actual water level observations over the last 10 years have shown that these forecasted river water levels have a $95 \%$ confidence level of $0,2 \mathrm{~m}$. Thus, the hydrological modelling has very good flood prediction capabilities (Fread, 1993). However, the water levels predicted by the hydrological model cannot satisfy the requirements of the decision support system for flood events. Indeed, it is hard for users to directly determine which houses, roads, and structures will be affected by the predicted flooding, because the model neither directly displays the areas affected by flooding, nor shows the difference between two flood events. In order to overcome this problem, it is necessary to interface the hydrological modelling software with a Geographic Information System (GIS).

In the past decades, engineers have developed many methods for delineating floodplain boundaries. Most of these methods are manual, tedious, and labour-intensive. With the advent of robust computer tools (GIS) and high accuracy Digital Terrain Model (DTM), automated floodplain delineation is achievable. Recently, several management systems for floodplain delineation have been developed and applied in the flood risk areas. These include floodplain delineation using watershed Modeling System (WMS) (EMRL, 1998), Arc/Info MIKE11_GIS (DHI, 2004), and HEC-GeoRAS (Ackerman, 2005). In this project, we used all of the above systems with CARIS software in order to implement floodplain delineation. CARIS (Computer Aided Resource Information System) develops and supports rigorous, technologically advanced geomatics software for managing spatial and non-spatial data. CARIS software supports Triangulated Irregular Networks and offers advanced algorithms for Digital Terrain models, such as interpolating elevations for given coordinates. In the next sections, we will show how the integration of CARIS with hydrological modelling software allows us to generate floodplain maps.

\section{Flood Prediction And Monitoring System}

In order to improve the current flood prediction system for the Saint John River, a new research has been initiated. Several provincial organisations in New Brunswick (Emergency Measures Organisation, NB Department of Environment, River-Watch and the University of New Brunswick) have been actively involved in this new research project titled "Decision Support for Flood Event Prediction and Monitoring (FEPM)".

The main objective of this research project is to build up a decision support system to improve the prevention, mitigation, response, and recovery from flood events.

The New Brunswick Department of Environment Hydrology Center monitors a wide range of information on factors affecting flooding such as snow conditions, temperatures, 
precipitation patterns, water levels and stream flow conditions by using a wide variety of telecommunication systems ranging from satellites to the telephone.

The New Brunswick Department of Environment Hydrology Center team uses hydrologic modelling software (DWOPER ${ }^{1}$ ) to predict water levels for the next 48 hours along the lower Saint John River Valley by processing climate data, weather forecast data, snow data, and flow data from approximately 60 water level gauges in New Brunswick.

The design of the system allows near real-time imagery of actual flood conditions to be overlaid on the base mapping and existing imagery, as well as overlays indicating 100-year flood extents. Map layers of transportation networks, hydrographic features, property boundaries, municipal infrastructure (e.g. power lines, natural gas lines) and contour lines can also be visualized.

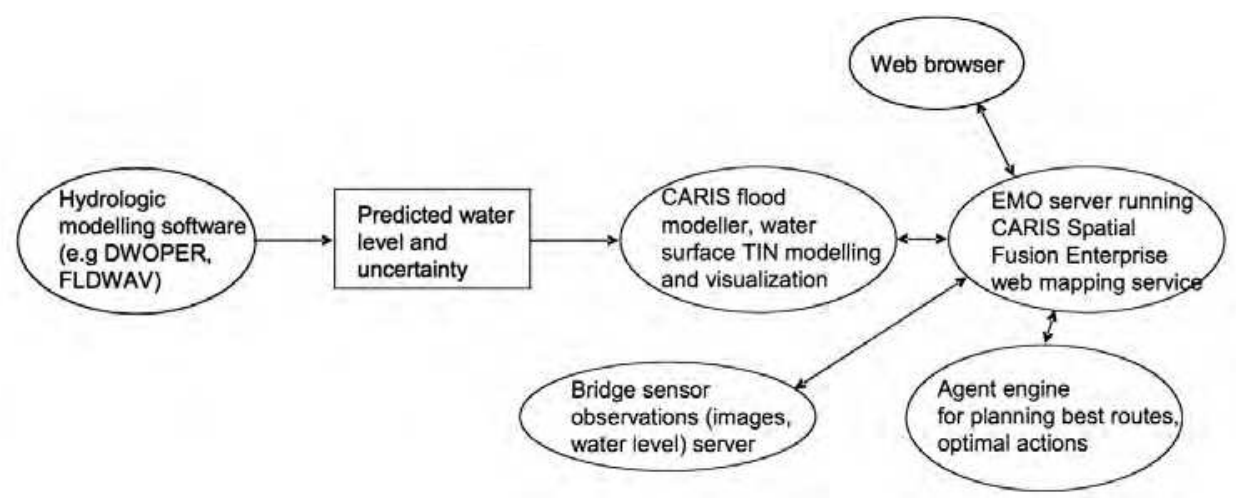

Fig. 7. Conceptual model of flood prediction and monitoring system

The final software products are integrated together within CARIS software as shown conceptually on Figure 7. Several provincial and research organisations in New Brunswick (University of New Brunswick, Emergency Measures Organization, NB Department of Environment, etc.) have been actively involved in the project. In this project, CARIS GIS software was used to implement floodplain delineation and online mapping.

\section{Integration of Hydrological Modeling And GIS}

The implementation that integrates hydrological modeling, Digital Terrain Modelling, and a GIS algorithm for floodplain delineation will be presented in the following section.

Floodplain delineation requires a high precision ground surface DTM. Analysis of available datasets shows that there are range and accuracy limitations among these datasets. It is therefore necessary to test and integrate these datasets in order to obtain a high accuracy Digital Elevation Model data. For this research, the accuracy of provincial elevation data

${ }^{1}$ DWOPER is a one-dimensional routing model developed by the Hydraulic Research Laboratory of the United States National Weather Service (Fread, 1992). 
and the city of Fredericton data were analyzed. High accuracy control points can be used to evaluate the accuracy of DTM data. This procedure is implemented by using CARIS GIS tools. Firstly, we generated a TIN model from elevation data (see Figure 8). Then using the CARIS GIS comparative surface analysis tool, the differences between the elevations of the control points and the interpolated elevation of the corresponding points were calculated. Finally, the statistical accuracy was computed using the methodology developed during previous floods in New Brunswick (CIWD, 1974) and (ENB-MAL, 1979).

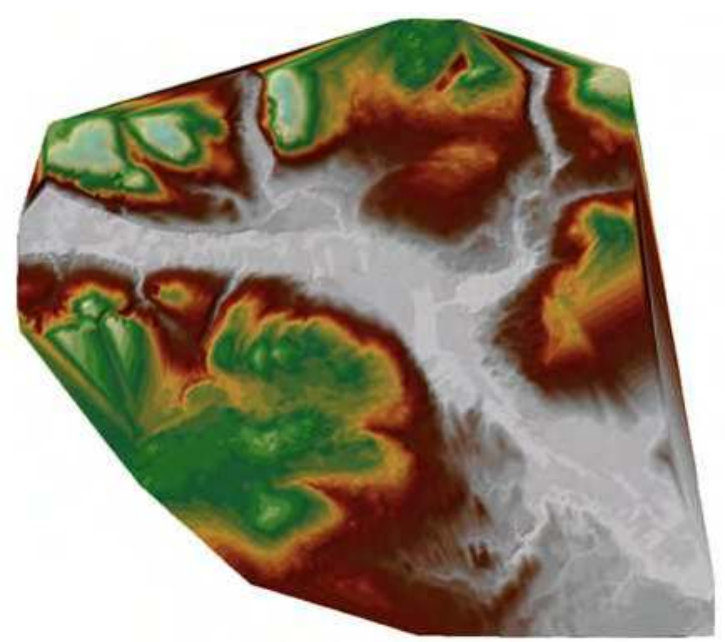

Fig. 8. DTM of the lower Saint John watershed

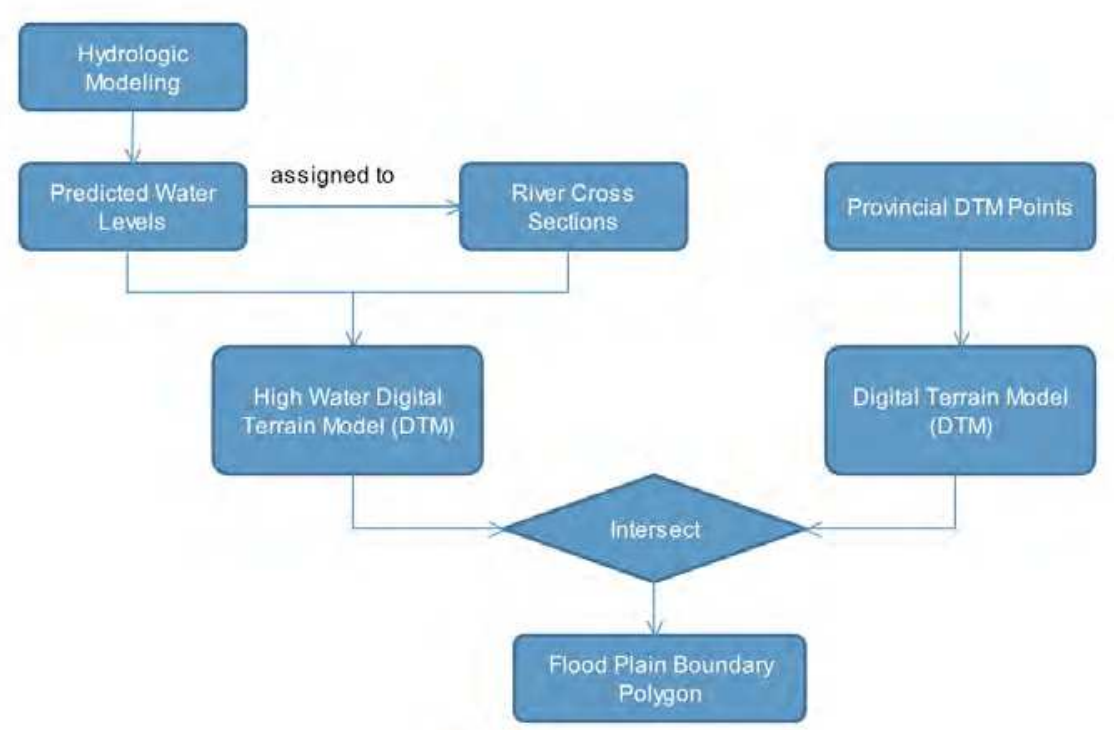

Fig. 9. The workflow of the calculation of predicted floodplain 
To support near real-time flood modelling, we developed the procedures for transmitting real time water level data from the New Brunswick Department of Environment - River Watch to the end users (see Figure 13). The water level data from the output of flood modelling by the Hydrology Centre in the Department of Environment are transmitted via FTP. The timestamp of new data is checked every 30 minutes for upload in the database. Then, the water level data are transferred to the FEPM Web Page for generating and displaying gauge bar graphs.

At the same time, the water level data are accessed by the software module for flood plain computations (Mioc et al., 2008). With the advent of robust GIS tools and high accuracy Digital Terrain Model (DTM), automated floodplain delineation is achievable (Noman et al., 2003). As shown on Figure 9, the most significant inputs for automated floodplain delineation $^{2}$ are the DTM (see Figure 8 ) and the water levels on the sections shown on Figure 10. The process considers the DTM and water levels at different locations to determine the direction and extent of flow over a floodplain for a given hydrologic event.

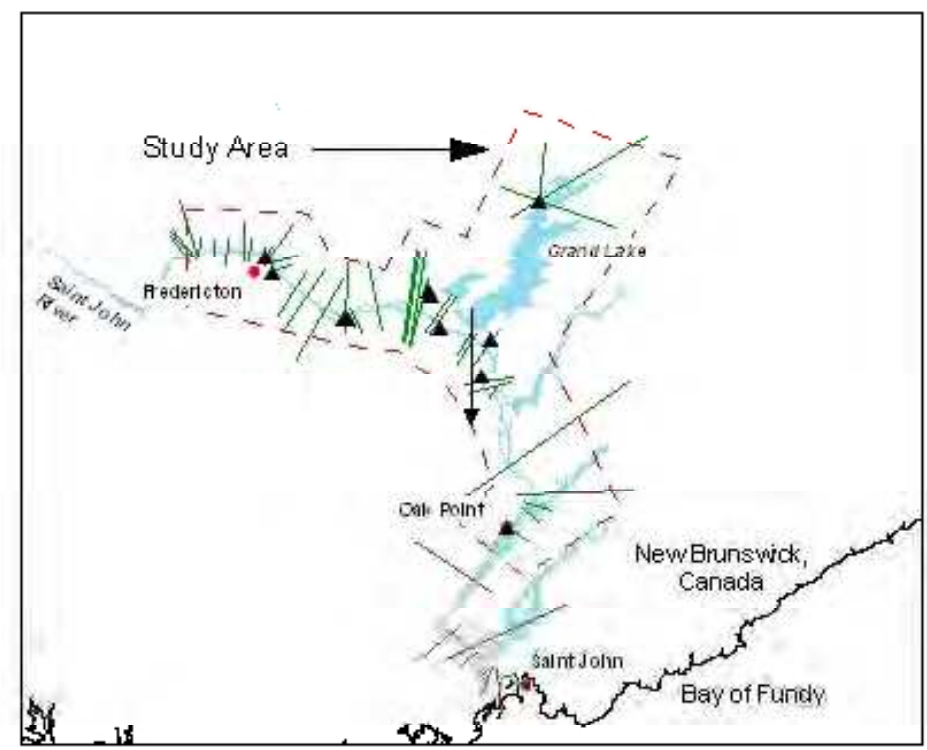

Fig. 10. Modeling water level surface using cross sections

The floodplain depth dataset is the primary output of this process. It indicates the high water mark and the depth of water inside the floodplain polygon, and is generated by computing the height difference between the water surface TIN with the ground surface DTM data. Based on the obtained flood depth data, the floodplain extent and depth maps can be generated. The intermediate parts of the process involve geo-referencing the water levels, extending the water levels to the probable floodplain area, and creating a TIN of the water surface. CARIS GIS allows users to create an irregular TIN or regular grid DTM, to calculate the accurately differences between two TINs or regular grid DTMs, to interpolate contours using a DTM, and

${ }^{2}$ Automated floodplain delineation is an excellent tool for producing floodplain extent maps (Noman et al., 2001; Noman et al., 2003). 
to display the DTM using the CARIS 3D Viewer program. These software functionalities were used for the development of the algorithm for floodplain delineation.

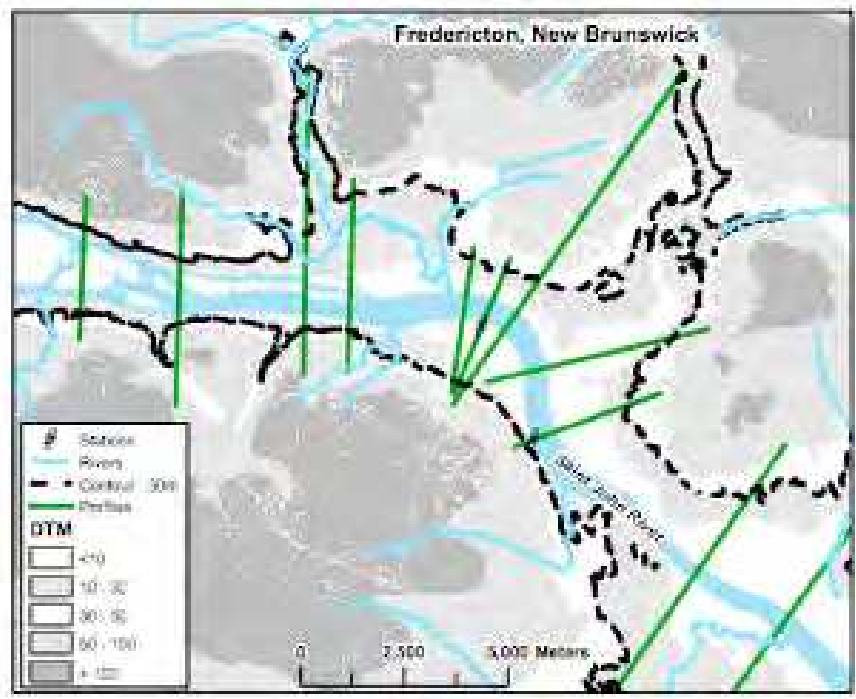

Fig. 11. Detailed zoom of the DTM and the floodplain of the area with the cross sections around Fredericton

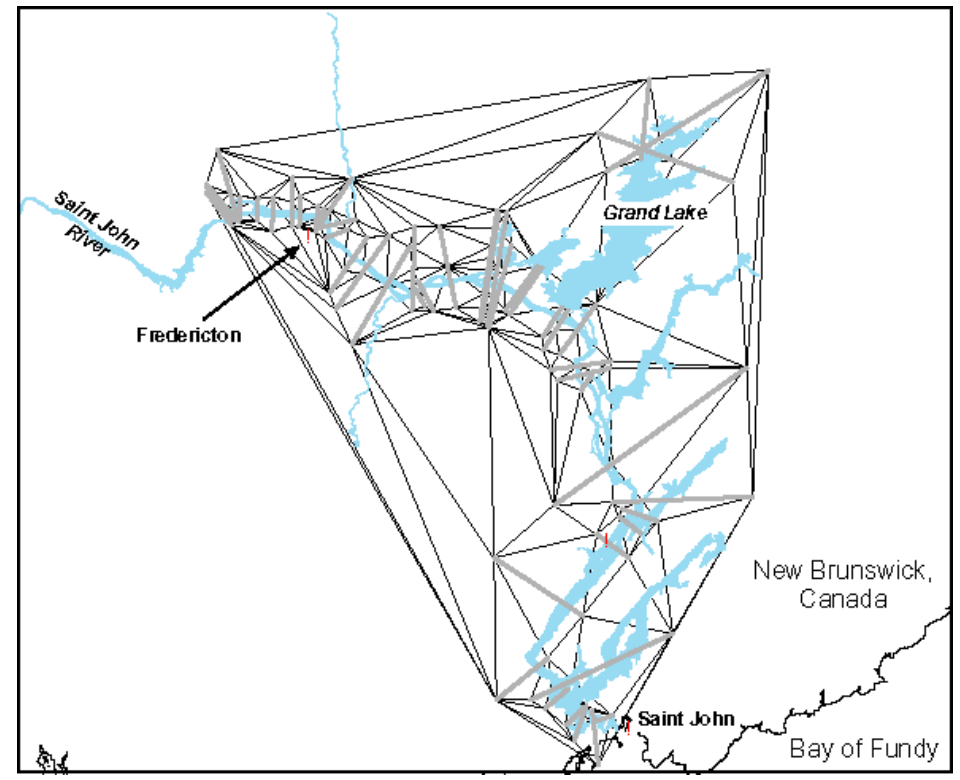

Fig. 12. Floodplain delineation process - computation of water surface TIN (the thick edges are constrained Delaunay edges corresponding to cross sections while the thin edges are Delaunay edges that do not correspond to cross sections) 
CARIS software provides an effective spatial analysis tool that calculates floodplain delineation and facilitates the mapping of flood events. As an example of floodplain delineation, Figure 11 shows the cross-sections used for the flooding event that took place in the Spring of 1973. Figure 12 shows the constrained Delaunay triangulation (see (Okabe et al., 2000) for an introduction to constrained Delaunay triangulations) used to compute the water surface. The flood plain is computed by interpolating linearly elevations and flood depths in the triangles. The cross sections are guaranteed to be present as edges of the triangulation, because they are the constrained edges. The cross sections are spaced in order to better evaluate the influence of confluents and effluents and their spacing decreases with the curvature of the river.

\subsection{Development of a Web-based interface for dynamic flood prediction monitoring and mapping}

CARIS Spatial Fusion was used to develop software for integration of satellite imagery and dynamic flood maps. Web map Interfaces that dynamically display maps of current and predicted flood events were developed and implemented.

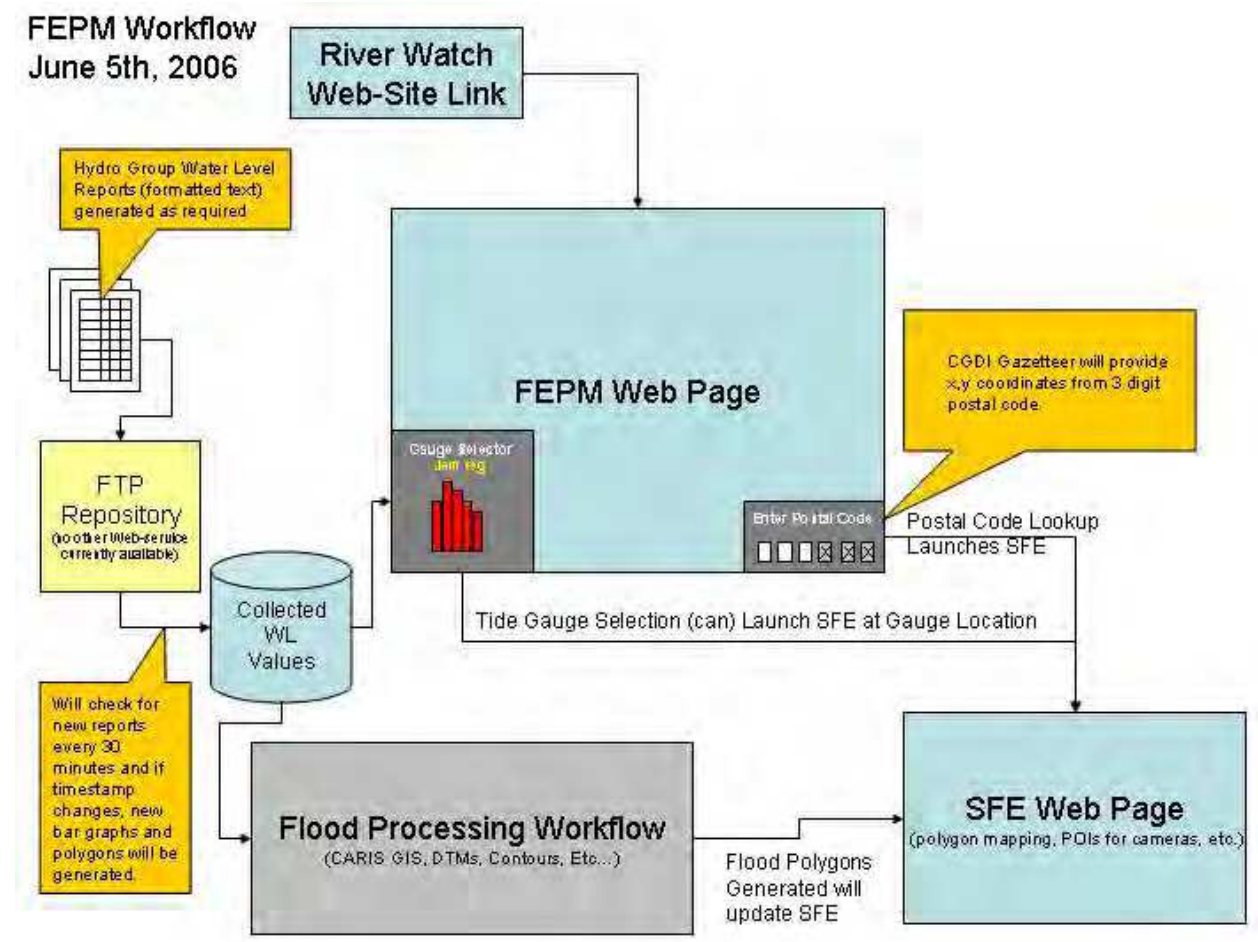

Fig. 13. Flood data processing diagram 


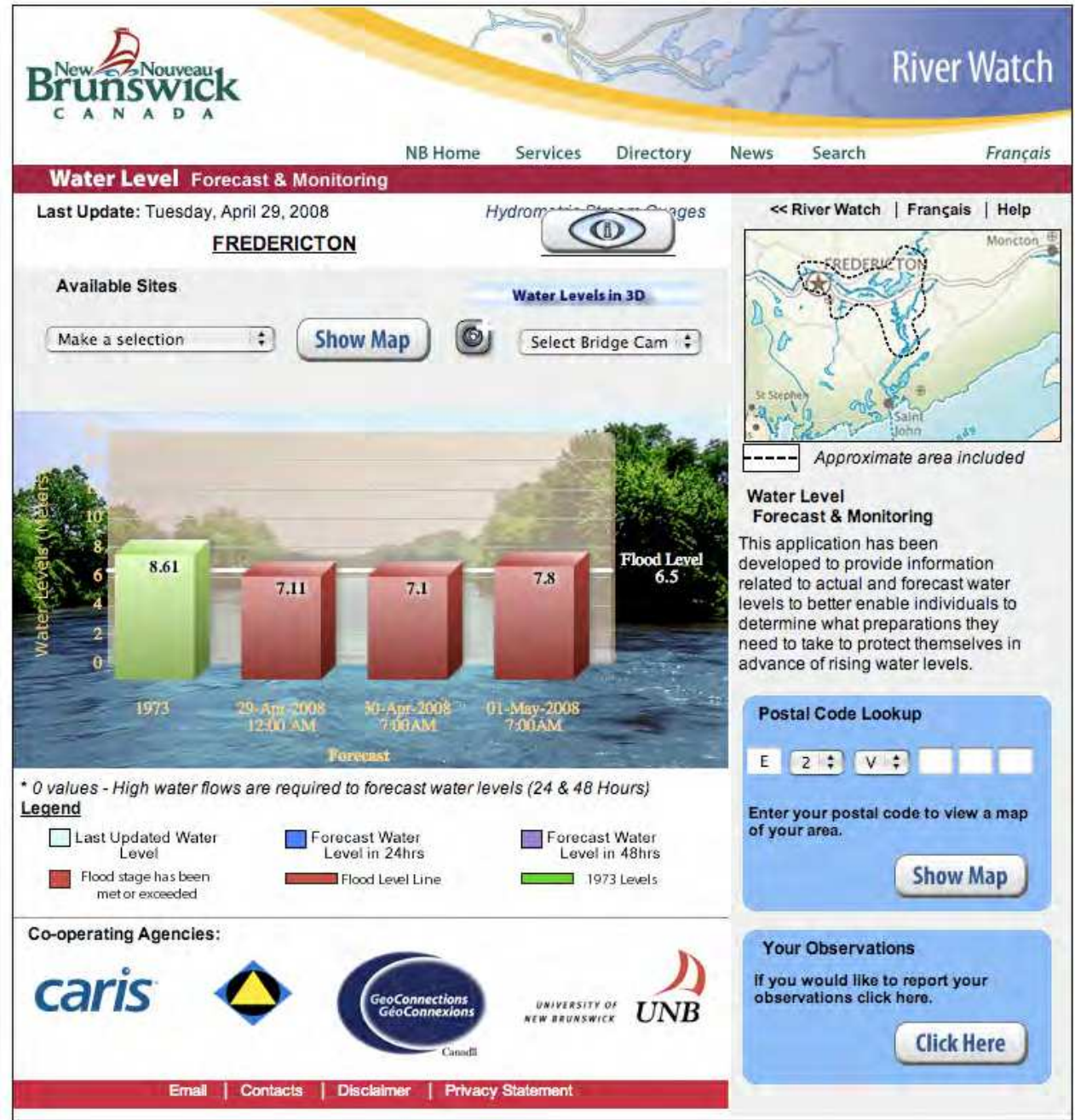

Fig. 14. New Brunswick River Watch Web site for flood warning in lower St. John River watershed

The architecture of the flood data processing is shown on Figure 13. The Web GIS software that we developed, allows for a spatial query based on 6-digit postal code (see Figure 14), so the users will be able to easily locate their area of interest. The web site allows one to display historical flood maps for twenty and hundred years average as well as for the catastrophic flood of 1973 (see Figure 15). 


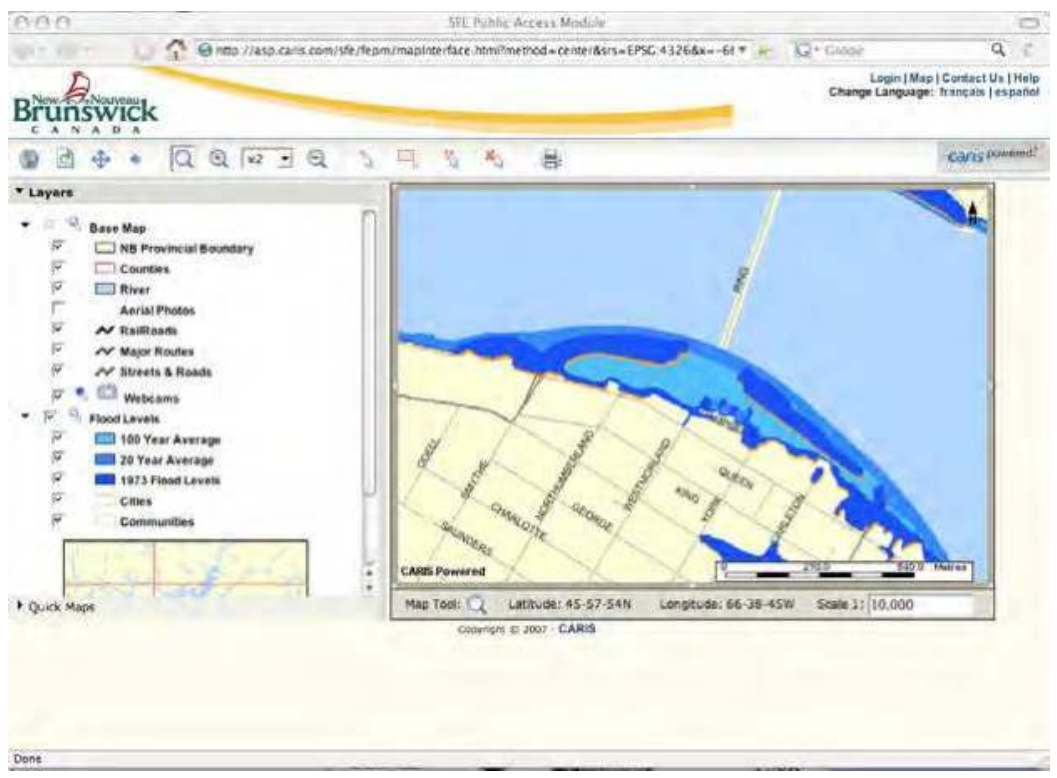

Fig. 15. Existing historical flood maps

The Web-GIS interface is also designed to calculate the flood polygon of current and predicted flood plains and display them as prediction maps (next 24 hours and 48 hours see Figure 16). Each layer of the web map is separate, allowing the overlay and visualization of transportation networks, hydrographical features, property boundaries, municipal infrastructure and contour lines.

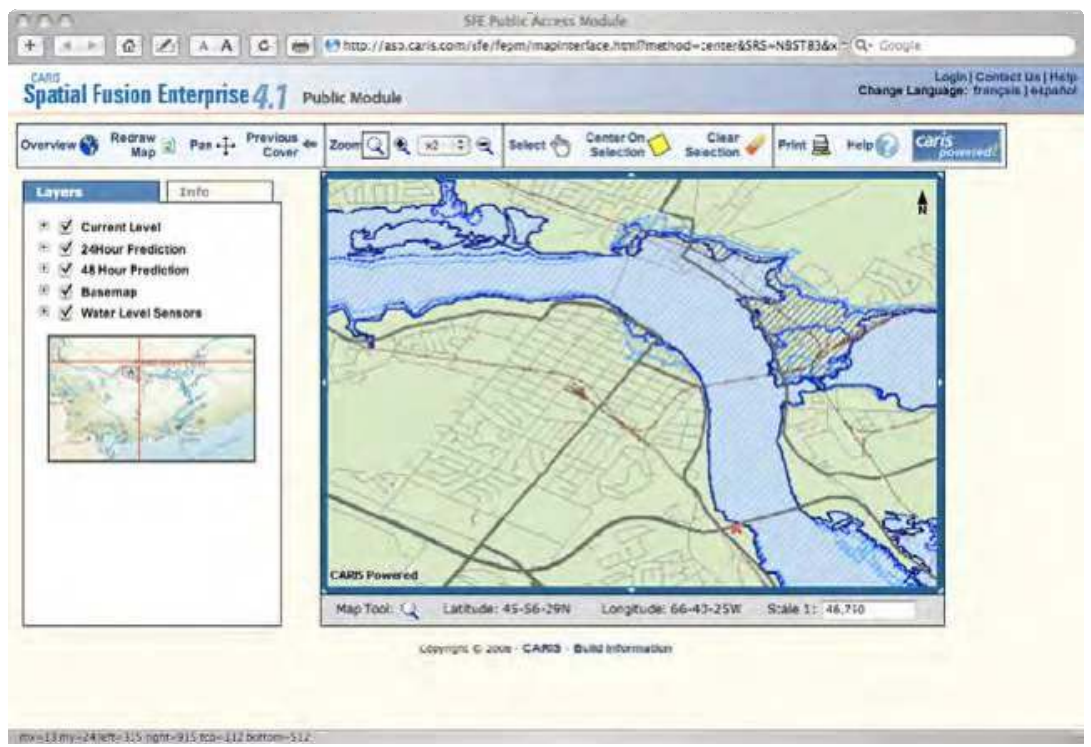

Fig. 16. Predicted flood maps 


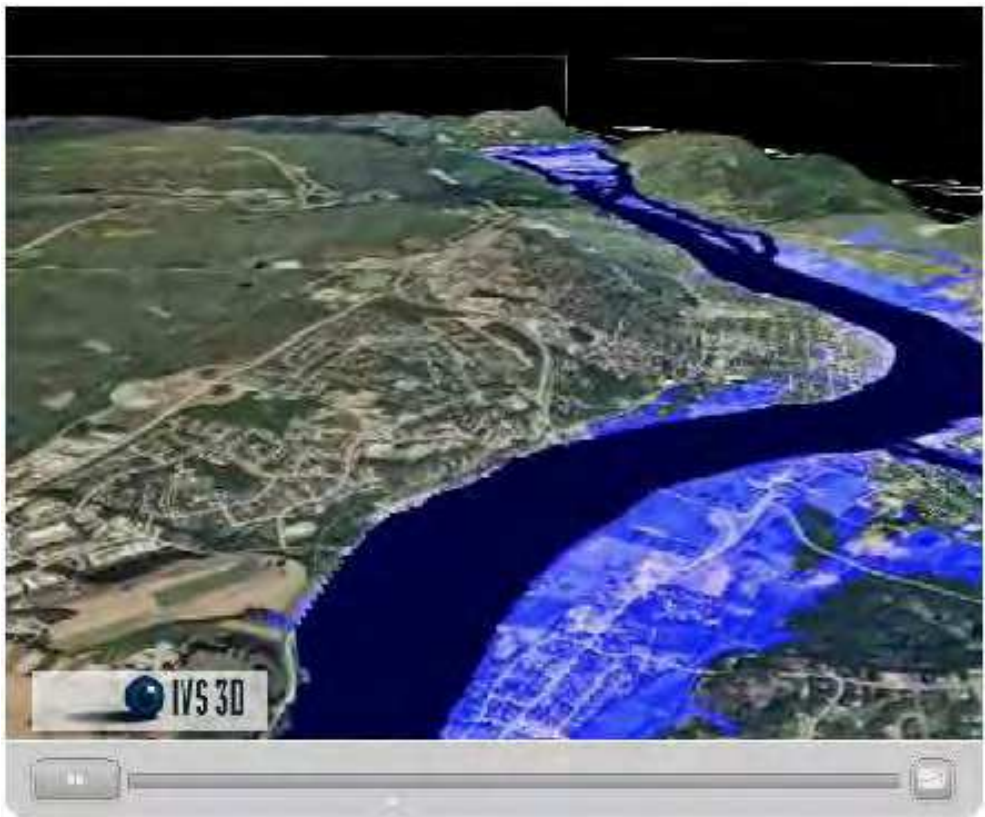

Fig. 17. Visualization of the flood in 1973 - Fredericton area

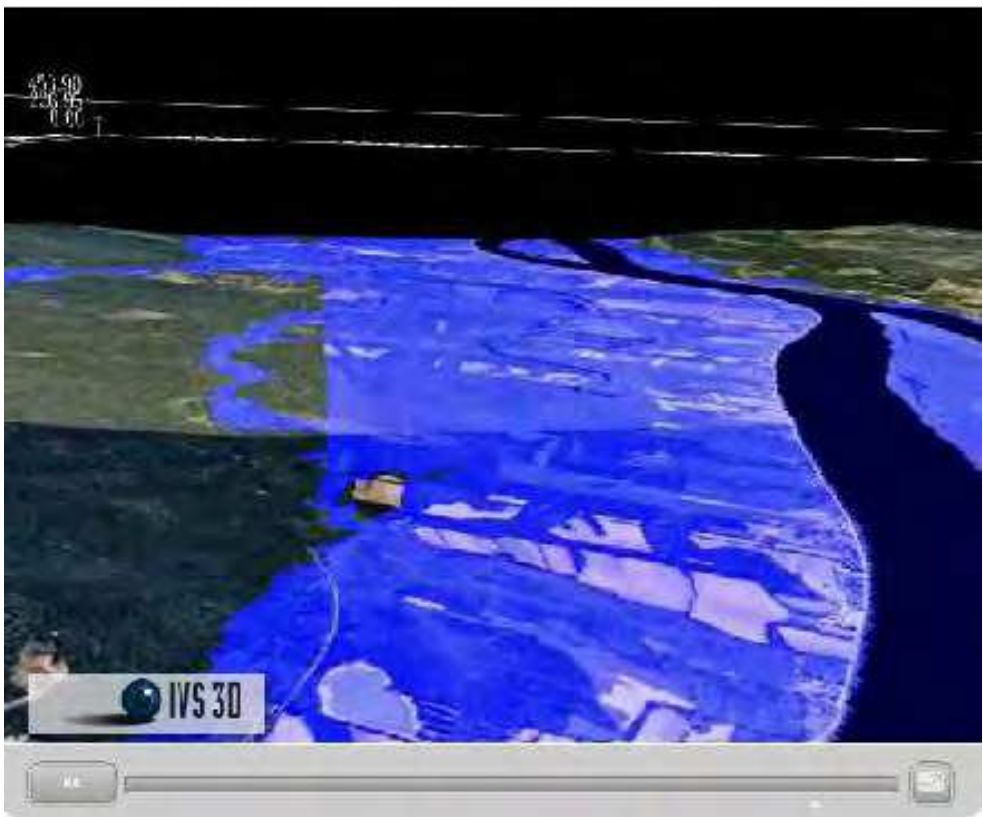

Fig. 18. Visualization of the flood in 1973 - rural area 
To better understand the spread and the impact of floods, the three-dimensional visualization of the flood of the Spring of 1973 was implemented (see Figures 17 and 18) using IVS3D ${ }^{3}$ software.

It allows users to visualize the major flood event that happened in the Spring of 1973 via "fly-through" animation. In this application the advanced software (from Interactive Visualization Systems) for dynamic visualization is used to interactively show the areas affected by the record high flooding in 1973.

The basic map layers are integrated with orthophotos and flood areas to create this realistic visualisation tool using IVS3D.

\section{Conclusions}

The Decision Support System for Flood Event Prediction and Monitoring implemented with web-mapping interfaces facilitates monitoring and prediction of flood events. It provides a basis for early warning and mapping of flood disasters. The general public can access the web site and browse the information in their area of interest. They can also visualize the impact of the flood events on the area where they live.

This research paper presents the integration of the DWOPER hydraulic model with the CARIS GIS system to dynamically compute and display near-real-time flood warning in the lower Saint John River valley. The main phases of development and implementation of a web-based GIS software for flood monitoring and prediction are presented as well.

With satellite imagery and a digital elevation model of the flood plain area, we can access a web-based prediction that models current flood events, and that can show how the water progresses based on the output from hydrological modelling for the next 24 and 48 hours along the lower Saint John River Valley.

This research provides the foundation for a revised decision support system that can result in improvements in the prevention, mitigation, response, and recovery from flood events along the lower Saint John River.

Further research is needed to improve the accuracy of digital terrain models by using LiDAR data, which will in turn improve the accuracy of hydrological modelling.

\section{Acknowledgments}

The authors would like to acknowledge the generous contribution of time, materials and resources to this project by the New Brunswick Department of Transportation.

This project was financially supported in part by the N.B. Emergency Measures Organization and the Canadian Department of Natural Resources Geoconnections program as well as the University of New Brunswick and the New Brunswick Innovation Foundation (NBIF).

The IT Division of the City of Fredericton provided datasets available for this project. The New Brunswick Department of Environment has provided data and expertise related to

3 The software (IVS3D) has been developed to allow the users to explore, analyze, manipulate and gain knowledge from their data by representing very large complex information in the best possible way - in an intuitive fashion - in the way that we perceive the real world everyday. This virtual reality allows new insight to be rapidly gained and more information to be extracted from the underlying data. (Source: http://www.ivs3d.com/companyinfo/about_ivs.html) 
hydrological modelling, and the NB Emergency Measures Organization helped with their expertise and additional funding for this project. CARIS provided the GIS software used in this project and contributed to the research project by providing the implementation of the web site and of all the related software components within CARIS Spatial Fusion. IVS provided the virtual reality software used in this project.

\section{References}

Ackerman, C.T. (2005). HEC-GeoRAS; GIS Tools for support of HEC-RAS using ArcGIS. Redlands: ESRI, 204 pages.

Al-Sabhan, W., Mulligan, M. \& Blackburn G.A. (2003). A real-time hydrological model for flood prediction using GIS and the WWW. Computers, Environment and Urban Systems, Vol. 27, pp. 9-32.

Canada Inland Waters Directorate, Atlantic Region [CIWD]. (1974). New Brunswick Flood, April-May, 1973, Ottawa: Inland Waters Directorate, Atlantic Region, 114 pages.

Danish Hydraulic Institute [DHI]. (2004). MIKE11 GIS reference and user manual.

Environmental Modeling Research Laboratory [EMRL]. (1998). Watershed modeling system (WMS) reference manual and tutorial.

Fread, D.L. (1992). Flow Routing, Chapter 10, Handbook of Hydrology. (Ed. E.R. Maidment). New York: McGraw-Hill. pp. 10.1-10.36.

Fread, D.L. (1993). NWS FLDWAV Model: The Replacement of DAMBRK for Dam-Break Flood Prediction. Dam Safety'93, Proceedings of the 10 th Annual ASDSO Conference, Kansas City, Missouri, pp. 177-184.

Fread, D.L., \& Lewis, J.M. (1998). NWS FLDWAV MODEL: Theoretical description and User documentation. Hydrologic Research Laboratory, Office of Hydrology, National Weather Service (NWS), Silver Spring, Maryland, USA, 335 pages.

Environment New Brunswick \& MacLaren Atlantic Limited, New Brunswick [ENB-MAL]. (1979). Canada-New Brunswick Flood Damage Reduction Program: Hydrotechnical Studies of the Saint John River from McKinley Ferry to Lower Jemseg. Fredericton, 116 pages.

Mioc, D., Nickerson B., McGillivray, E., Morton A., Anton, F., Fraser, D., Tang, P., \& Liang, G. (2008). Early warning and mapping for flood disasters. Proceedings of $21^{\text {st }}$ ISPRS Conference, China, Bejing, 2008, 6 pages.

Moore, R.J., Bell, V.A., \& Jones, D.A. (2005). External Geophysics, Climate and Environment - Forecasting for flood warning. C. R. Geoscience, Vol. 337, pp. 203-217.

Noman, N.S., Nelson, E.J., \&. Zundel, A.K. (2001). Review of automated floodplain delineation from digital terrain models. Journal of Water Resources Planning and Management, Vol. 127, No. 6, pp. 394-402.

Noman, N.S., Nelson, E.J., \& Zundel, A.K. (2003). Improved Process for Floodplain Delineation from Digital Terrain Models. Journal of Water Resources Planning and Management, Vol. 129, No. 5, pp. 427-436.

Okabe, A., Boots, B., Sugihara, K., \& Chiu, S.N. (2000). Spatial Tessellations - Concepts and Applications of Voronoi Diagrams. (2nd ed.). Chichester: John Wiley. 671 pages.

Sanders, R., Shaw, F., MacKay, H., Galy, H., \& Foote, M. (2005). National flood modeling for insurance purposes: using IFSAR for flood risk estimation in Europe, Hydrology and Earth System Sciences. Vol. 9, No. 4, pp. 449-456. 


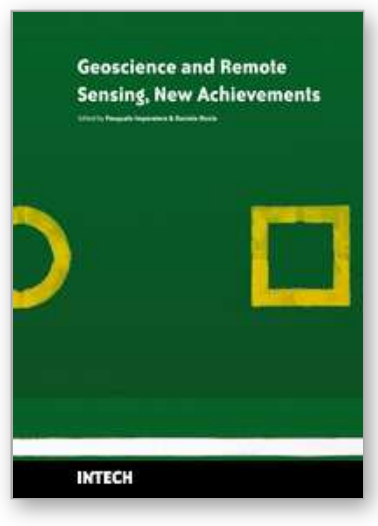

\author{
Geoscience and Remote Sensing New Achievements \\ Edited by Pasquale Imperatore and Daniele Riccio
}

ISBN 978-953-7619-97-8

Hard cover, 508 pages

Publisher InTech

Published online 01, February, 2010

Published in print edition February, 2010

Our planet is nowadays continuously monitored by powerful remote sensors operating in wide portions of the electromagnetic spectrum. Our capability of acquiring detailed information on the environment has been revolutionized by revealing its inner structure, morphology and dynamical changes. The way we now observe and study the evolution of the Earth's status has even radically influenced our perception and conception of the world we live in. The aim of this book is to bring together contributions from experts to present new research results and prospects of the future developments in the area of geosciences and remote sensing; emerging research directions are discussed. The volume consists of twenty-six chapters, encompassing both theoretical aspects and application-oriented studies. An unfolding perspective on various current trends in this extremely rich area is offered. The book chapters can be categorized along different perspectives, among others, use of active or passive sensors, employed technologies and configurations, considered scenario on the Earth, scientific research area involved in the studies.

\title{
How to reference
}

In order to correctly reference this scholarly work, feel free to copy and paste the following:

D. Mioc, B. Nickerson, F. Anton, E. MacGillivray, A. Morton, D. Fraser, P. Tang and A. Kam (2010). Early Warning And On-Line Mapping For Flood Events, Geoscience and Remote Sensing New Achievements, Pasquale Imperatore and Daniele Riccio (Ed.), ISBN: 978-953-7619-97-8, InTech, Available from: $\mathrm{http}: / / w w w . i n t e c h o p e n . c o m / b o o k s / g e o s c i e n c e-a n d-r e m o t e-s e n s i n g-n e w-a c h i e v e m e n t s / e a r l y-w a r n i n g-a n d-o n-$ line-mapping-for-flood-events

\section{INTECH}

open science | open minds

\section{InTech Europe}

University Campus STeP Ri

Slavka Krautzeka 83/A

51000 Rijeka, Croatia

Phone: +385 (51) 770447

Fax: +385 (51) 686166

www.intechopen.com

\section{InTech China}

Unit 405, Office Block, Hotel Equatorial Shanghai

No.65, Yan An Road (West), Shanghai, 200040, China 中国上海市延安西路65号上海国际贵都大饭店办公楼 405 单元

Phone: +86-21-62489820

Fax: +86-21-62489821 
(C) 2010 The Author(s). Licensee IntechOpen. This chapter is distributed under the terms of the Creative Commons Attribution-NonCommercialShareAlike-3.0 License, which permits use, distribution and reproduction for non-commercial purposes, provided the original is properly cited and derivative works building on this content are distributed under the same license. 